\title{
An Evaluation of Oxalate Content in Cassava Roots and Sweet Potato Tubers in Areka, Ethiopia
}

\author{
Beriso Mieso Buta \\ As sociate Researcher at EIAR,WGARC \\ Ethiopia \\ Email: berimieso03 [AT] gmail.com
}

\begin{abstract}
Oxalic acid (or its dissociated form oxalate) is a result of protein metabolism and is among the important nutrients in the human diet. Regular consumption of large amounts of food with high oxalate contents over a long period mav result in nutrient deficiencies notably calcium and contribute to kidney stone formation. The aim of current research is to determine some physicochemical characteristics as well as the oxalate content of cassava in addition to sweet potato grown in Areka, Ethiopia using titration and $U V$-visible spectrophotometric methods. The moisture content of dry flour and fresh roots of cassava was found to be 10.33 and $55.27 \%$, respectively, while the moisture content of dry flour and fresh tuber of sweet potato was 9.07 and $68.47 \%$, respectively. The ash content of the flour sample of cassava and sweetpotato was 3.60 and $4.13 \%$, respectively. The pH of the flour sample of cassava and sweet potato was 6.23 and 6.13, respectively. Oxalate content determination was done using titration and UV-visible spectrophotometer methods. The oxalate level of samples using the titration method gave 77.66 and $197.90 \mathrm{mg} / 100 \mathrm{~g}$ for cassava and sweetpotato, respectively. By the UV-visible spectrophotometer, the oxalate content was 151.19 and 153.56 mg/100g for cassava and sweet potato, respectively. Statistical analysis on the generated data indicated that all physicochemical investigated in this study have significance difference at $p \leq 0.05$.
\end{abstract}

Keywords---- Cas sava, oxalate, physicochemical, sweet potato, UV-visible spectrophotometer

\section{INTRODUCTION}

Oxalic acid (or its dis sociated formoxalate) is a result of protein metabolismand is among the important nutrients in the human diet. Common dietary sources of oxalic acid include tuberous crops such as sweet potato (Ipomoea batatas L.), godere (taro) (Colacasia esculanta L.), yams (boyna) (Dioscorea spp.), cas sava (Mahinot esculenta) and the others. Its levels is type, age of plant tis sue and growth rate dependant [1]. Evidence showed that calciumoxalate and hyperoxaluria is a primary risk factor for $75 \%$ of all kidney stones [2]. These plants are energy generating plants in many poor counties which have high growth and urbanization s peeds. They functions as common diet for many low incoming populations. The high land root and tuber plants (cassava, sweet potato, taro, and boyna) has crucial benefits in global diet stability. [3].

Cassava (Manihot esculenta) belongs to the family Euphorbiaceous which has two cotyledon. It is a plant which stays 1-3 year to mature and its roots used as food and contains high starch.It stores edible material in the tuber and provides energy in the human diet in the form of carbohydrates [4,5]. It ranks sixth most important crop after wheat, rice, maize, potato, and barley in the world. Its mature edible roots can be stored in the ground for up to three years and contributed consistently to food security [6]. The crop is widely cultivated in the southern part of Ethiopia particularly in the Amaro-Kello area (Gedeo zone) as a staple food and has played a significant role in alleviating the food crisis during harsh weather and domestically referred to as "YeinchetBoye" or "YeferengBoye" [7].

Sweet potato (Ipomoea batatas L.) is originated around northern South America [8]. It is an herbaceous, perennial plant and its tuber is an important source of carbohydrate. Yellow fleshed sweet potato is a indicator of vitamin A as well as has high carotene [9]. It is common plant used for diet stability and grown in most parts of Africa with high population density. [6].

The objective of the research is determining some physicochemical properties as well as the oxalate of cas savaand sweet potato grown in Areka, Ethiopia using titration and UV-visible spectrophotometric methods. 


\section{EXPERIMENTAL}

\section{Sample preparation}

Tubers used in this activity were obtained in Areka Agricultural Research center farmland. One variety of cassava roots from releas ed varieties namely $\mathbf{H W - 4}$ and One variety of s weet potato tubers from releas ed varieties namely $\mathbf{H W - 8 3}$ were obtained in Areka Agricultural Research center farmland. Sampling area was located at the latitude of $7.064100^{\circ} \mathrm{N}$, longitude $37.687007^{\circ} \mathrm{E}$, and elevation of $1775.20 \mathrm{~m}$ asl. After collection, the samples were taken to Wondo genet Agricultural Research Center, Natural Products Laboratory for preparation for further analyses. The samples were then peeled and washed properly with distilled water before cutting into small pieces followed by air drying for 5 days and milled to powder by grinder. Powdered flours were sieved to obtain fine powder packaged and stored for further analyses.

\section{Physicochemical evaluation of raw and powdered samples}

\section{Mois ture content}

The mois ture content of raw cas sava roots and $\mathrm{s}$ weet potato tubers and their powdered forms was identified as established official method of 925.05.9 ( AOAC2000).

The dishes was dried at $130{ }^{\circ} \mathrm{C}$ for $1 \mathrm{~h}$ in an oven. Each plate was weighed using the digital electronic balance. $5 \mathrm{~g}$ of the samples were measured into all plates. Aliqu ot come together uniformly then moisture was removed at hundred ${ }^{0} \mathrm{C}$ within six hour. when 6hr was completed the weight of dry samples recorded. Water capacity (mois ture) was obtained as follows:

Moisture $(\%)=\frac{(\mathrm{M} 2-\mathrm{M} 3)}{(\mathrm{M} 2-\mathrm{M} 1)} \mathrm{X} 100$

$M_{1}$ : plate mas s , $M_{2}$ : plate mass and fresh sample, and $M_{3}$ :plate mas s and dry sample

\section{Ash content}

The total ash content of the raw cassava roots and sweet potato tubers as well as their powdered forms obtained by the established technique 941.12 (Ass ociation of Analytical Chemists 2000).

The crucibles cleaned and ignited at $550^{\circ} \mathrm{C}$ in the furnace for $3 \mathrm{hr}$. Then the crucibles removed heat in freezer. Weight of every crucibles were weighed by electronic balance $(M)$ and about $2.5 \mathrm{~g}$ flour of tuber crops was measured in each crucible $\left(\mathrm{M}_{2}\right)$. Crucibles dried at $120{ }^{\circ} \mathrm{C}$ for $1 \mathrm{~h}$ in a drying oven. The crucibles put in a furnace at $550{ }^{\circ} \mathrm{C}$ for $1 \mathrm{hr}$. The crucibles taken in furnace and heat removed. Five droplets of dis tilled $\mathrm{H}_{2} \mathrm{O}$ was poured to each of the crucibles and put in to furnace at $550{ }^{\circ} \mathrm{C}$ within time length of 30 minutes. Then the crucibles taken from the furnace as well as cooled. 5 drops of distilled $\mathrm{H}_{2} \mathrm{O}$ and $\mathrm{HNO}_{3}$ poured into all crucibles. The crucibles taken (put) in to the furnace till the sample color was converted to. Next, the crucibles taken out of furnace then put in freezer and finally crucible weight meas ured as.

Total ash content obtained as follows:

$$
\operatorname{Ash}(\%)=\frac{(\mathrm{M} 3-\mathrm{M} 1)}{(\mathrm{M} 2-\mathrm{M} 1)} \times 100
$$

$M_{1}$ : crucible weight, $M_{2}$ : crucible weight and flour before inserting furnace, $M_{3}:$ a mass of the crucible and the sample after taking out from the furnace.

\section{pH}

The device was standardized by $\mathrm{pH} 4$ and pH 7 standard solution. $5 \mathrm{~g}$ sample dispersed into $25 \mathrm{ml}$ of dis tilled $\mathrm{H}_{2} \mathrm{O}$ and stand for $30 \mathrm{~min}$ with continuous stirring. The $\mathrm{pH}$ meter electrode was dipped to solution by continuous stirring till the constant value was recorded. The values were written when device indicates constant reading Triplicate measurements were made in all cases and the result was the average of the triplicate measurements. 


\section{Titration method}

Titration method was doneby method described in [10]. The procedure contains following steps.

Digestion: $2 \mathrm{~g}$ of Aliquot was dissolved with one hundred ninety milliliter of distilled $\mathrm{H}_{2} \mathrm{O}$ by using two hundred fifty milliliter volumetric flask. 10 milliliter six molar hydrochloric acid poured to above mixture then solution heated at $100^{\circ} \mathrm{C}$ with time length of one hr. Finally the heat of solution removed, filled to volumetric flask volume mark and filtered.

Oxalate precipitation: An amount of one hundred twenty five milliliter of above solution was taken in beaker. 4 drops of methyl red indicator poured. Concentrated $\mathrm{NH}_{4} \mathrm{OH}$ solution was added drop by drop till color change of solution (s almon pink color to a faint yellow). The content heated to $90^{\circ} \mathrm{C}$ then removed heat and filtered to discard impurity. The solution digested with ninety ${ }^{0} \mathrm{C}$ and ten milliliter five percent calcium chloride solution poured by stirring througly. Then,the solution removed heat and kept whole night at $5^{\circ} \mathrm{C}$. A content centrifuged with velocity of of two thousand five hundred revolution per minute within five minutes. A supernatant separated and the precipitate completely mixed with ten milliliter twenty percent volume by volume sulfuric acid solution.

Permanganate titration: A filtrate obtained fromthe digestion of two gramof sample filled to three hundred milliliter. Aliquot of one hundred twenty five milliliter of above solution heated close to boiling, then titrated with $0.05 \mathrm{M}$ standardized potassium permang anate, the solution changes color to a faint pink which persisted for thirty second.

Oxalate was obtained as follows

Oxalate content $=\frac{\mathrm{T} \times \mathrm{Vme} \times \mathrm{DF}}{\mathrm{ME} \times \mathrm{MF}} \times 10^{5}$

The abbreviations in the above formula represents

$\mathrm{T}$ for Titer value of $\mathrm{KMNO}_{4}(\mathrm{ml}), \quad$ Vme for $\mathrm{v} / \mathrm{m}$ equivalent $\left(1 \mathrm{ml}\right.$ of $0.05 \mathrm{M} \mathrm{KMNO}_{4},=0.00228 \mathrm{~g}$ of anhydrous oxalic acid), Df for dilute factor (Vt/A that is, total volume of titrate/ Aliquot used =2.4),

for mas s of sample used,

ME for molar equivalence of $\mathrm{KMNO}_{4}$ in oxalate concentration in $\mathrm{g} / \mathrm{dm}^{3}=5$.

\section{UV-Visible spectrophotometric method}

The UV-Visible spectroscopic method was adopted as documented according to [11]. Total oxalate was measured by weighing $1.0 \mathrm{~g}$ sample of dried tubers in a beaker followed by the addition of $150 \mathrm{~mL}$ water containing $27.5 \mathrm{ml} 6 \mathrm{M} \mathrm{HCl}$ two drops of capry lic alcohol (octanol), the mixture was brought to boil for $25 \mathrm{~min}$. The heated mixture was cooled, added to $250 \mathrm{ml}$ volumetric flask, and filled to mark. A mixture filtered with Whatman No. 541 filter paper. The first $80 \mathrm{ml}$ filtrate was discarded and the rest was retained for analy sis. A volume of $10 \mathrm{ml}$ of this filtrate was evaporated to near dry ness at $40-45^{\circ} \mathrm{C}$ in a vacuumoven, and mixed in ten milliliter of $0.01 \mathrm{M}$ sulfuric acid. Oxalate in the sample was analyzed using a UV-Visible spectrophotometer.

\section{Data analysis}

Significance differences in physicochemical parameters level of thecassavaand sweet potato roots were subjected to t-test using Microsoft Excel s oftware.

\section{RESULTS AND DISCUSSION}

\section{Physicochemical characteristics}

Different physicochemical parameters of the cassava roots and the sweet potato tubers were tested and the results are as shown in Table 1.

Table 1. Phy sicochemical parameters of cassava roots and s weet potato tubers $(n=3)$ 


\begin{tabular}{|c|c|c|c|c|}
\hline Sample code & $\begin{array}{l}\text { a Moisture content (fresh } \\
\text { tuber }(\%) \text { ) }\end{array}$ & $\begin{array}{l}\text { a Moisture content (dry } \\
\text { flour }(\%) \text { ) }\end{array}$ & ${ }^{\mathrm{a}} \mathrm{Ash}$ content $(\%)$ & ${ }^{\mathrm{a}} \mathrm{pH}$ \\
\hline HW -83 & $68.47 \pm 0.12$ & $9.07 \pm 0.12$ & $4.13 \pm 0.46$ & $6.13 \pm 0.16$ \\
\hline HW -4 & $55.27 \pm 0.92$ & $10.33 \pm 0.12$ & $3.60 \pm 0.40$ & $6.23 \pm 0.16$ \\
\hline
\end{tabular}

Where: ${ }^{a}$ is Values mean \pm SD of triplicate flour and fres $h$ tuber samples

HW -83 repres ents one variety of s weet potatoes fromreleased varieties

$\mathrm{HW}-4$ repres ents one variety of cassava fromreleased $v$ arieties

\section{Mois ture content}

The mois ture of the cassava roots as well as sweet potato tubers was determined for two different sample conditions. The first one was mois ture content of the fresh tuber sample which was carried out immediately after sample collection. The second one was moisture content of the dry flour which was carried out after the samples were dried and milled into flour. Table 1 showed that the moisture content of fresh roots of cassava which was $55.27 \pm 0.92 \%$ and that of sweet potato tuber was $68.47 \pm 0.12 \%$. Mois ture of flour of cassava was $10.33 \pm 0.12 \%$ and that of s weet potato was $9.07 \pm 0.12 \%$. According to the finding of [12] the moisture content of 10 selected local varieties, s weet potato from Benin was ranged between 53.89 and $74.1 \%$. This indicated that the present study result $(68.47 \pm 0.12 \%)$ was within the range of this finding. According to the report of [13], the mois ture content of the other two cas sava varieties namely Qulle and Kello varieties were found to be $9.47 \pm 0.47$ and $8.48 \pm 0.02 \%$, respectively. The moisture content of the present study was $10 \pm 0.12 \%$ which was slightly greater than the observed values in this study. The small difference maybe because of the difference in varieties of cas sava samples and the method of drying as well as the mois ture content of the dried cassava roots before it was milled into flour. According to [14] report, moisture of the sweet potato flour samples was found between (8.06$12.86 \pm 1.13 \%$ ). The moisture sweet potato flour sample was $9.07 \pm 0.12 \%$ which was similar to values obtained by previous work. The mois ture content of powdered samples is heavily dependent on the initialmois ture content of the raw samples, method of drying, drying conditions including the temperature and duration of drying and rate of moisture loss during drying.

\section{Ash content}

From Table 1 the ash content of the cassava root was $3.60 \pm 0.40 \%$ and the sweet potato tubers were $4.13 \pm 0.46 \%$. According to the report of [13], the as h content of the other two cas sava varieties namely Qulle and Kello varieties were found to be $3.45 \pm 0.26$ and $2.43 \%$, res pectively. The ash content was $3.60 \% \pm 0.40$. This finding was slightly greater than the values of the two reported varieties. The small difference in the ash content value may be as a result of the difference in the varieties of the cassava root s amples. According to the finding of [12], the ash content of ten selected local varieties of sweet potato from Benin ranged between 2.56 and $4.70 \%$. This indicated that the present result $(4.13 \pm 0.46 \%)$ lies within this range of as content of s weet potato obtained fromBenin.

\section{pH}

From Table 1 the $\mathrm{pH}$ of cas sava was $6.23 \pm 0.16$ and that of sweet potato was $6.13 \pm 0.16$. The report of [13] indicated that the $\mathrm{pH}$ of two cassava varieties namely Qulle and Kello varieties were found to be 6.19 \pm 0.01 and $6.53 \pm 0.01$, respectively. When we compared with the present study result $(6.23 \pm 0.16)$ the result was slightly greater than the pHof Qulle variety and less than that of Kello variety. The slight difference in the $\mathrm{pH}$ value may be arises from a varietal difference of cassava samples. According to the report of [14], the $\mathrm{pH}$ value of twelve varieties of Ghanaian s weet potatoes was ranged from $5.89 \pm 0.01$ to $6.21 \pm 0.01$. The $\mathrm{pH}$ value of the present study $(6.13 \pm 0.16)$ was within the range of finding.

\section{Oxalate content}

Oxalate of flour of the cassava roots and sweet potato tubers was determined by using titration and UV-visible spectrophotometric methods in this study. The results were presented in Table 2. 
Table 2. Oxalate content of cassava roots and sweet potato tubers $n=3$ )

\begin{tabular}{lcc}
\hline Sample code & \multicolumn{2}{c}{${ }^{\mathrm{a}}$ Oxalate $(\mathrm{mg} / 100 \mathrm{~g})(\mathrm{db})$} \\
\cline { 2 - 3 } & \multicolumn{1}{c}{ titration method } & UV-vis method \\
\hline HW-83 & $197.90 \pm 20.80$ & $153.56 \pm 0.68$ \\
HW-4 & $177.66 \pm 19.70$ & $151.19 \pm 0.34$ \\
\hline
\end{tabular}

Where: ${ }^{\text {as }}$ Values mean \pm SD of triplicate flour samples

$\mathrm{db}$ is a dry basis

HW-83 represents one variety of sweet potatoes fromreleased varieties

HW-4 represents one variety of cassava from released varieties

The oxalate content of the cassava roots and the sweet potato tubers was $177.66 \pm 19.70$ and $197.90 \pm 20.80 \mathrm{mg} / 100 \mathrm{~g}$, respectively. The oxalate level of the cas sava variety in this study was greater than the level of oxalate of cas savavariety obtained by [15] which was from $1.3 \pm 0.010$ to $2.3 \pm 0.002 \mathrm{mg} / 100 \mathrm{~g}$ and the level of oxalate in the two cas sava varieties which was reported by [13] which was $24.93 \pm 0.08$ for Qulle variety and $86.18 \pm 0.10$ for Kello variety. The difference in the oxalate level between the experimental value and the reported value maybe as a result of the varietal difference between the two samples, an agro-ecological difference like temperature, climate, soil type, the difference in the performance of the analytes (chemicals) used while performing tests and even the difference in analyst who performed the tests. The mean value of oxalate content for sweet potato (HW-83) in the present study was $197.90 \pm 20.80 \mathrm{mg} / 100 \mathrm{~g}$ which was higher than that reported by [16]. The difference in the oxalate level between the experimental value and reported value for the sweet potato tubers may be because of the varietal difference between the sweet potato samples used, an agro-ecological difference like temperature, climate, and soil type.

The oxalate level was $151.19 \pm 0.34$ and $153.56 \pm 0.68 \mathrm{mg} / 100 \mathrm{~g}$ for the cassava roots and the sweet potato tubers respectively by UVSpectrophotometry method. The level of oxalate in this study was greater than the report of [17] the oxalate content of Nigerian tubers which was found in the range of $(0.46-2.56 \mathrm{mg} / 100 \mathrm{~g} \mathrm{FW})$. The difference may be due to the difference in sample location, agro-ecological difference, and climatic condition including soil type.

\section{CONCLUSION}

In this study Oxalate level of cas sava and s weet potato grown in Areka, Ethiopia was analyzed by titration and UV-Visible spectrophotometric methods. Firs tly physicochemical parameters like mois ture content of fresh tuber and dry flour samples, ash, and pHof flour samples were analyzed. The results indicated that almost all of the physicochemical parameters of all four tuber crops were within the range of different research findings done on the same samples. The oxalate content of these tuber crops was also within the range of different reports.

\section{ACKNOWLEDGMENT}

I am grateful to acknowledged the Wondo Genet Agricultural Research Center for financial support. Next and for most I greatly acknowledge my colleague Mr.Abdela Befa for critically supporting me while I write th is manuscript fromstart to end.

\section{REFERENCES}

1. Abdollahi, S., et al., Nutritional StatusofPatients with Chronic Kidney Disease in Iran: A Narrative Review. Journal of Nutrition and Food Security, 2018. vol. 3, pp. 51-59

2. Albihn, P., and G. Savage (2001). The effect of cooking on the location and concentration of oxalate in three cultivars of New Zealand-grown oca (Oxalis tuberosa Mol). Journal of the Science of Food and Agriculture, 81: 1027-1033.

3. Frossard,E., et al., The challenge of improving soil fertility in yam cropping systems of West Africa: a review. Frontiers in Plant Science, 2019.8.

4. Joy,E.-E., et al., Seasonal variations in the chemical and functional properties of starchesfrom local and improved cassava varieties in high rainfall region of Nigeria. Journal of Food, Agriculture, and Environment, 2007. 5: p. 36-42. 
5. Mweta, D., et al., Some properties of starches from cocoyam (Colocasia esculenta) and cassava (Manihot esculenta Crantz) grown in Malawi. African Journal of Food Science, 2008. 2: p. 102-111.

6. Motsa, N., A. Modi, and T. Mabhaudhi, Sweet potato (Ipomoea batatas L.) as a drought-tolerant and food security crop. South African Journal of Science, 2015. 111:p. 1-8.

7. Gebremiche, M., A. Nebiyu, and T.M. Beyene, Estimates of Genetic Components for Yield and Quality of Cass ava (Manihot esculenta Crantz) Genotypes at Jimma, Southwest Ethiopia. International Journal of Plant Breeding and Genetics, 2015.9: p. 1-12.

8. Takamine, K., M.-M. Ma, and F.O. Ogutu, Chapter 5 -Sweet potato dietary fiber, in Sweet Potato, T.-H. Mu and J. Singh, Editors. 2019, Academic Pres s. p. 117-148.

9. Sharma, R., et al., Impact evaluation indicators of an Integrated Pest Management prog ram in vegetable crops in the subtropical region of Jammu and Kashmir, India. Crop Protection, 2015. 67: p. 191-199.

10. Iwuoha, C.I. and F.A. Kalu, Calcium oxalate, and physicochemical properties of cocoyam (Colocasia esculenta and Xanthosoma sagittifolium) tuberflours as affected by processing. Food Chemis try, 1995. 54(1): p. 61-66.

11. Kaushal, P., V. Kumar, and H. Sharma, Utilization oftaro (Colocasia esculenta): A review. Journal of Food Science and Technology, 2013.52.

12. Sanoussi, F., et al., Possibilities of sweet potato [Ipomoea batatas (L.) Lam] value chain upgrading as revealed by the physicochemical composition often elites landraces ofBenin. AFRICAN JOURNALOF BIOTECHNOLOGY, 2016. Vol. 15: p.pp.481-489.

13. Abera, T., et al., Effect of Proces sing on Physicochemical Composition and Anti-NutritionalFactors of Cas sava (Manihot Esculenta Crantz) Grown in Ethiopia Ijsid International Journal of Science Innovations and Discoveries An International peer Review-Journal for Science. International Journal of Science Innov ations and Discoveries, 2013. 5: p. 212-222.

14. Olatunde, G., et al., Quality attributes of sweetpotatoflour as influenced by variety, pretreatment, and drying method. Food Science \& Nutrition, 2015. 4.

15. Obueh, H. and K. Ekanah, Comparative Studyon the Nutritional andAnti-Nutritional Compositions of Sweet and Bitter Cassava Varieties for Garri Production. Journal of Nutrition and Health Sciences, 2016. 3.

16. Ekanah, K. and H. Obueh, A study of the oxalate, phytate, and cyanide contents of selected Nigerianfoods and diet in Akwa Ibom and Cross River states of Nigeria *a. Journal of Food Science and Technology -Mysore-, 2013. 4: p. 2141-5455.

17. Durowoju, O. and O. Popoola, Oxalate content of some Nigerian tubers using titrimetric and UVspectrophotometric methods. Academia Journal of Agricultural Res earch, 2014. 02. 